all other covariates, the unexplained Indian advantage only reduced by a quarter (from 1.08 to 0.71 parent SDQ points) and remained highly significant. This Indian advantage was largely confined to families of low socio-economic position.

Conclusion The Indian mental health advantage is real and is specific to externalising problems. Family type and academic abilities mediate part of the advantage, but most is not explained by major risk factors. Likewise unexplained is the absence in Indian children of a socio-economic gradient in mental health. Further investigation of the Indian advantage may yield insights into novel ways to promote child mental health and mental health equity in all ethnic groups.

\section{P1-436 RELATIONSHIP BETWEEN ADHD SYMPTOMS AND OFFENDING BEHAVIOUR AND BREACHES OF PRISON DISCIPLINE AMONG INCARCERATED YOUTHS IN SCOTALND}

doi:10.1136/jech.2011.142976g.26

V Gordon, ${ }^{*}$ D Williams, P Donnelly. University of St Andrews, St Andrews, Fife, UK

Introduction Prisoner mental health is an increasingly important health concern. An often neglected condition among youth prisoners is $\mathrm{ADHD}$, which not only has implications for general health and well-being, but is also associated with an increased risk of antisocial and unlawful behaviour (including violent offences). The paper reports a study that investigates the relationship between $\mathrm{ADHD}$ symptoms and violent conduct in male youth prisoners in Scottish prisons.

Method The study included 57 male youth offenders incarcerated in three Scottish prisons and 58 male (student) non-offenders, aged 18-21 years. Self-reported ADHD symptoms were measured using the Conners' Adult ADHD Rating Scale and information on the nature and number of prison breaches of discipline was provided by the Scottish Prison Service.

Results The youth offender group showed significantly greater total $\mathrm{ADHD}$ symptom scores than the non-offenders. More specifically, scores on the DSM-IV hyperactivity-impulsive subscale were significantly greater in offenders than non-offenders. Moreover, a variety of subscales showed a greater correlation with violent compared to non-violent breaches of prison discipline.

Conclusion The study found that Scottish male youths currently incarcerated in Scottish prisons show greater levels of $\mathrm{ADHD}$ symptoms than a group of male (student) non-offenders. Moreover, there was some evidence suggesting that self-reported hyperactivity and impulsivity differentiated violent and non-violent breaches of prison discipline. In conclusion, given the association of $\mathrm{ADHD}$ with violent conduct, it is imperative that $\mathrm{ADHD}$ symptoms are acknowledged as risk factors for anti-social and violent behaviour and are subsequently addressed in rehabilitation efforts.

\section{P1-437 RELATIVE VALIDITY OF A SHORT FOOD FREQUENCY QUESTIONNAIRE FOR ASSESSING NUTRIENT INTAKE VS 3-DAY WEIGHED DIET RECORDS IN YOUNG JAPANESE WOMEN}

doi:10.1136/jech.2011.142976g.27

${ }^{1} \mathrm{C}$ Goto, ${ }^{*}{ }^{2} \mathrm{Y}$ Tokudome, ${ }^{3} \mathrm{~N}$ Imaeda, ${ }^{4} \mathrm{~K}$ Kuriki, ${ }^{5} \mathrm{~S}$ Tokudome. ${ }^{1}$ Nagoya Bunri University, Inazawa, Aichi, Japan; ${ }^{2}$ Nagoya University of Arts and Sciences, Nisshin, Aichi, Japan; ${ }^{3}$ Nagoya Women's University, Nagoya, Aichi, Japan; ${ }^{4}$ University of Shizuoka, Shizuoka, Shizuoka, Japan; ${ }^{5}$ National Institute of Health and Nutrition, Tokyo, Japan

Introduction We have executed a validity test on our short food frequency questionnaire (FFO) in "middle-aged" Japanese, but not "young women" yet, and here examined.
Methods One hundred and twenty five young women in Aichi Prefecture, Japan, completed the FFO and 3 day-weighed diet records (3d-WDRs) in 2009. We compared intakes of energy and 26 nutrients computed with the FFO against those with $3 \mathrm{~d}-W D R s$ as reference.

Results Participant's means (SD) of age and BMI were $20.3(0.5)$ years and $23.3(2.3) \mathrm{kg} / \mathrm{m}^{2}$, respectively. No significant difference was found between energy intakes of 1579 (221) and 1576 (258) $\mathrm{kcal} /$ day according to the FFQ and 3d-WDRs. Pearson's correlation coefficients between each nutrient intake derived from the FFQ and 3d-WDRs were 0.29 (energy), 0.18 (protein), 0.26 (fat), 0.28 (carbohydrate), 0.53 (calcium), 0.20 (iron), 0.21 (sodium), 0.33 (potassium), 0.31 (carotene), 0.30 (Vitamin A), 0.36 (Vitamin D), 0.36 (soluble dietary fibre), 0.32 (insoluble dietary fibre), 0.31 (total dietary fibre) and 0.23 (n-3 polyunsaturated fatty acids), respectively. Median percentages for exact agreement and disagreement according to quartile classification of each nutrient intake measured with both methods were 25.6 and 6.4 , respectively.

Conclusions Similarly to our previous study, we showed considerably high relative validity values for consumption of macro- and micro-nutrients estimated with the FFQ vs those assessed with $3 \mathrm{~d}$ WDRs. The FFO therefore appears applicable for categorising individuals according to consumption of energy and the selected nutrients in dietary studies of young Japanese women.

\section{P1-438 THE UROTHELIAL CARCINOMA RISKS OF RADIATION, SMOKING AND OCCUPATIONAL EXPOSURES: A CASE- COHORT STUDY WITH STRATIFIED SAMPLING AMONG A-BOMB SURVIVORS}

doi:10.1136/jech.2011.142976g.28

${ }^{1}$ E J Grant, ${ }^{2} \mathrm{~T}$ Kubo, ${ }^{1} \mathrm{R}$ Sakata, ${ }^{1} \mathrm{~J}$ B Cologne, ${ }^{1} \mathrm{~A}$ Suyama, ${ }^{1} \mathrm{~K}$ Ozasa. ${ }^{1}$ Radiation Effects Research Foundation, Hiroshima, Japan; ${ }^{2}$ University of Occupational and Environmental Health, Fukuoka, Japan

Introduction Primary risk factors for urothelial carcinomas (UC) include smoking, occupational exposures to aromatic amines (AA) and polycyclic aromatic hydrocarbons (PAH). Radiation risk estimates of the A-bomb survivors indicate the bladder is highly radiosensitive. However, concerns persist as to whether high smoking rates or occupational exposures may have influenced these estimates. The purpose of this study is to re-estimate radiation risk estimates of UC while adjusting for smoking and occupational exposures to AAs and PAHs.

Methods A case-cohort study with stratified sampling of A-bomb survivors who completed a lifestyle survey. The sub-cohort consisted of 3195 persons sampled from an overall cohort of approximately 70000 with an average age at entry of 52.7 years. There were 356 incident UCs between 1967 and 2001. Occupational exposures were assigned using a job exposure matrix from the US National Occupational Exposure Survey. An industrial hygienist assigned US Standard Industrial Classification codes (2-digit) based on questionnaires. Preliminary risk estimates were derived from Cox proportional hazards with robust estimates of variance.

Results The HR for 1 grey of radiation dose was 1.58 (95\% CI 2.54 to 5.21). After adjusting for smoking and occupational exposures, the radiation HR was 1.49 (95\% CI 1.01 to 2.18). The smoking HR was highly significant $(2.86 ; 95 \%$ CI 2.00 to 4.09$)$. No association was observed with occupational exposures.

Conclusions Results are preliminary. Improvements in variance estimation and the addition of occupational codes are still outstanding. However, these results indicate that previously reported risk estimates of UC are not largely biased by smoking or occupational exposures. 